\title{
NEUTRONS AND RADIO-ELEMENTS AND THEIR BIOLOGICAL APPLICATIONS*
}

\begin{abstract}
$7 \mathrm{HE}$ spontaneous radioactivity of a number of heavy elements has been known for a generation, but it is only within the last decade that attempts to induce radioactivity in stable elements hare succeeded. Since the first successful experiments of Curie and Joliot, however, progress has been rapid and radioactive isotopes of the majority of the stable elements have been made. Now that powerful high-voltage plants are available, the quantity in which these artificial radioelements may be obtained is in some cases com. parable with the quantities of natural radioelements which are available, and the artificial radio.elements are already beginning to compete with the naturally radioactive elements as sources of beta- and gamma-rays for physical purposes, and will probably soon be used on an appreciable scale for medical purposes for which radium is at present in use.
\end{abstract}

Economically, there is probably at present not much to choose between the use of radium and of artificial radio-elements, the interest charges on the capital invested in radium being of the same order as the costs of maintenance of a cyclotron. The special importance of the use of artificial radio-elements in biological experiments lies in the possibility of using active isotopes of elements already present in the organism and taking part in its metabolism.

There are at present two methods of producing artificial radio-elements in quantity, the first being the direct bombardment of inactive material with protons, deuterons or alpha particles, and the second the activation of inactive materials with slow neutrons, the latter being produced by the slowing down in paraffin or water of neutrons generated in some reaction such as the bombardment of deuterium or beryllium with deuterons. Either method thus starts with the production of a beam of fast charged particles. The direct way of obtaining such a beam is to generate the requisite high voltage and apply it to a vacuum tube in which the ions are accelerated. This was the method used by Cockcroft and Walton, and the Cavendish Laboratory now has a generator of the Cockcroft and Walton type operating at two million volts. Apparatus of this type, in which the full voltage is applied to the accelerating

- Based on a discussion in Section A (Mathematical and Physical Sciences) of the British Association, which took place on August 31 and September 1 , those taking part being Dr. J. Lawrence, Dr. $\mathrm{W}$. B. Lewis, and Dr. J. Read and Dr. L. H. Gray. tube, would become very cumbersome at still higher voltages, on account of the large clearances necessary to prevent spark-over, and further extension of this method is likely to proceed along the lines of enclosing the apparatus in a high-pressure or oil-filled tank. When considerations of finance limit the voltage to a million or less, however, it is the best type of machine, since the fact that ion currents as high as one milliampere may be obtained counter-balances to some extent the diminished disintegration yield at these relatively low voltages.

Dr. J. Read and Dr. L. H. Gray have installed a machine of this type at the Mount Vernon Hospital, London, producing neutrons by the $\mathrm{D}+\mathrm{D}$ reaction and operating reliably at 300 $400 \mathrm{kv}$. with ion currents up to 900 microamperes. This plant has so far given an output of neutrons equal to that produced by 30 curies of radon plus beryllium, which is sufficient for investigating the more sensitive biological reactions of radiation. It was built at a cost of $£ 600$, and has been operated for two years at the very modest figure for maintenance of $\mathfrak{1} 80$ per annum, both figures being of the order of one tenth the corresponding costs for a large cyclotron. The deuterons are drawn from a low-voltage arc, and after acceleration fall on the target, which is at earth potential. The target is a film of heavy paraffin wax deposited on a copper plate water-cooled on its underside; the material to be irradiated can be brought to within $1 \mathrm{~cm}$. of the focal spot. The bombardment of the paraffin wax rapidly causes chemical changes to a less saturated hydrocarbon of only half the deuterium content, with consequent loss in neutron output. After the initial fall, however, the output remains constant for some months of use.

When particles of very high energy are required, the method par excellence is the cyclotron developed by Prof. E. O. Lawrence, in which ion energies of millions of volts are attained by repeated impulses of $100 \mathrm{kv}$. or so given twice per revolution as the ions execute a spiral path between the poles of a large electromagnet. The largest cyclotron at present in operation is that recently completed at Berkeley, California, and with this machine deuterons of $18 \mathrm{Mv}$. and alpha particles of $38 \mathrm{Mv}$. have been obtained. The neutron intensity from this machine is adequate for therapy at distances from the target of the order of $\mathrm{l}$ metre. 
With the smaller Berkeley cyclotron, which gives particles of about half this energy, a considerable amount of biological work has already been done. The effect of neutrons in killing mice, Drosophila eggs, bacteria and fern spores, in producing chromosome abnormalities and in inhibiting growth in wheat seedlings has been com. pared with similar effects produced by $\mathrm{X}$-rays and gamma-rays. The effects are in general qualitatively similar, but suggest that in most of these cases the biological effect per ionization in the tissue is greater for neutrons than for X-rays. That this is not a general phenomenon is shown, however, by the experiments of Timoféeff-Ressovsky and Zimmer, who find that neutrons are somewhat less effective per ionization than $\mathrm{X}$-rays in the production of gene mutations in Drosophila. The investigation of the dependence of the biological efficiency per ionization upon the specific ionization of the ionizing particle is one of the most promising methods of investigating the mechanism of the biological action of radiations.

Following the experiments on animal and plant material, the treatment of cancer patients with neutrons has now begun at Berkeley. A satisfactory degree of collimation of the neutron beam, which is essential for cancer treatment, has been obtained by the use of a lead-lined channel in a water tank. It is not yet known how successful the use of neutrons will be in the treatment of cancer, compared with X-rays. Encouraging therapeutic results have, however, already been obtained in another direction, namely, in the treatment of leucæmia by the oral administration of radiophosphorus. A marked fall in the white cell count and improvement in the condition of the patient follows the dose, which is repeated at intervals when called for by a rise in the white cell count.

Numerous uses for the artificial radio-elements in experimental biology have already been found, particularly in investigating metabolic problems. The admixture of a small quantity of a radioactive isotope with a larger mass of inactive atoms serves as a tracer for these atoms, and enables one, for example, to find out what proportion of a particular element administered orally is excreted immediately, and what proportion is taken up by each organ. If sodium chloride containing some radioactive sodium is swallowed, sufficient will find its way into the hand in ten minutes to affect a Geiger counter shiclded from the rest of the body. Injected intravenously in one arm, its presence can be detected in the other arm some twenty seconds later, an experiment having possible applications in the investigation of circulatory disorders.

\section{THE HABITS OF SALMON}

$\mathrm{I}^{\mathrm{N}}$ recent years, intensive investigation of the life-history and habits of salmon and trout has been carried out in all the countries where the species are of importance. The results of the investigations were recognized by a symposium on salmon at the summer meeting of the American Association for the Advancement of Science in Ottawa in 1938, and by a morning devoted to the subject at the recent meeting of the British Association at Dundee.

Salmon spend from one to five, and normally two or three, years as parr in fresh water. Here recent investigations have shown that growth is not entirely seasonal but that, contrary to expectation, a marked slowing down, if not cessation, of growth occurs in August when conditions might normally be expected to be favourable. This coincides with the experience of trout anglers, to whom August is often anathema, and of fish farm operators who, however, recognize a close connexion between water temperature and food intake and digestive activity. Mr. K. R. Allen has already noticed this fact and, at the Dundee meeting, Dr. K. Carpenter argued that the diminution of growth and, concomitantly, of the intake of food organisms, was directly associated with a marked decrease in the number of organisms available in the streams.

It has long been recognized that in their second year, or for those that remain so long, in their third autumn, certain male salmon parr may become sexually mature and may spawn with adult females. That the spermatozoa of these precocious fishes functioned successfully was shown at least fifty years ago. Prof. J. H. Orton and Mr. J. W. Jones have recently pointed out that a quite considerable proportion of the male parr may be ripe, and Mr. Jones stated at Dundee that by dissection it is possible to trace during the smolt stage in the following year those which had spawned some six months earlier. The significance of this precocity is not yet understood. It is unlikely that it forms an important contribu. tion to the continuance of the stock, but it is quite possible that it may affect the length of life spent in the sea. The fish concerned may return after a 